\title{
Mathematical Modeling of Thermal Management at Different Atmospheric Pressure Conditions
}

\author{
Juan Carlos Beltrán-Prieto, Luis Antonio Beltrán-Prieto \& \\ Long Huynh Bach Son Nguyen
}
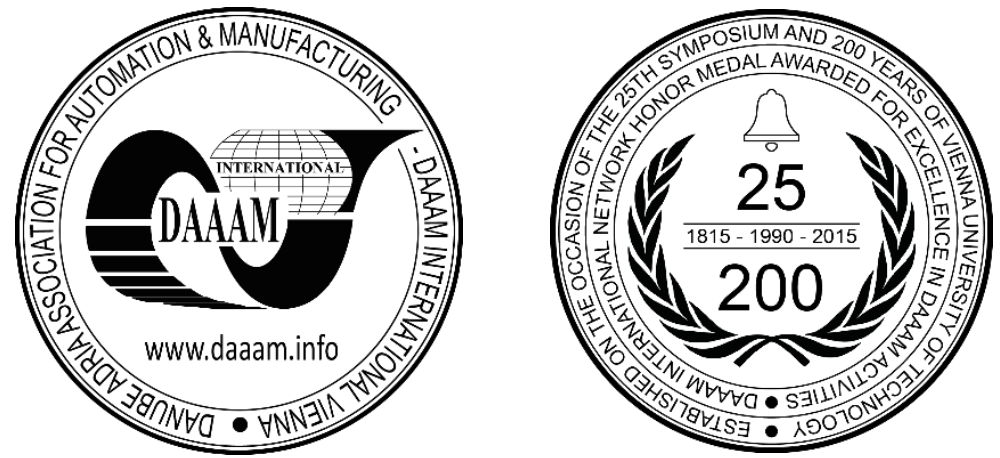

This Publication has to be referred as: Beltran Prieto, J[uan] C[arlos]; Beltran Prieto, L[uis] A[ntonio] \& Long Huynuh Bach Son, N[guyen] (2017). Mathematical Modeling of Thermal Management at Different Atmospheric Pressure Conditions, Proceedings of the 28th DAAAM International Symposium, pp.0988-0995, B. Katalinic (Ed.), Published by DAAAM International, ISBN 978-3-902734-11-2, ISSN 1726-9679, Vienna, Austria DOI: $10.2507 / 28$ th.daaam.proceedings.137

\begin{abstract}
Cooling process is an important element in the correct functioning of all electronic devices. While some components can resist high temperatures, others are damaged during overheating conditions. We performed numerical simulation to study the temperature variation during cooling process of electronic devices that are subject to the effect of different pressures. Commonly the correct functioning of instruments is tested under specific conditions given by the location of the manufacturer but generally the consumer uses the device in a different region. Cooling process performed by convection uses the air provided by a fan. Fluid properties such as kinematic viscosity are influenced by pressure and the effect in cooling is demonstrated by analyzing the variation of surface temperature at different pressures. This study allows us to understand the importance of fluid flow speed in controlling the heating rate. We performed numerical simulation at different air speed $(10-20 \mathrm{~m} / \mathrm{s})$ and pressure $(77-100 \mathrm{kPa})$ which corresponds to the elevation of cities that are located between $31 \mathrm{~m}$ and $2240 \mathrm{~m}$., additionally we studied the maximum amount of power dissipation as a function of air velocity with radiation contribution and without radiation effect.
\end{abstract}

Keywords: Air flow velocity; Nusselt parameter; atmospheric pressure; kinematic viscosity; power dissipation

\section{Introduction}

Forced convection is a process in which heat transfer occurs due to simultaneous conduction and fluid flow. During the process of cooling caused by high velocities of flow, laminar regime is present in the interphase of the surface and the fluid while turbulent flow is present far from the surface. The mathematical model of cooling process is frequently expressed by differential equations. In some cases, analytical solutions exist but frequently numerical methods are required. One of the most common cases of cooling is caused by air flowing in parallel direction of a hot solid plate [1]. As the air flows, the temperature profile changes at different cross sections normal to the plate surface. The direction of heat flows is always from regions of higher to regions of lower temperature. Energy is transferred through an area in the form of heat at a rate proportional to the temperature gradient normal to the area. [2] 
Intensive research has been performed about cooling systems. Heating and cooling experiments were performed by Vogel and coworkers, who studied heat transfer in a rectangular enclosure with different widths and heights [3]. Earlier studies by Bareiss and Beer described the observation of two-regime models, a conduction regime was observed firstly, followed by a quasi-steady convection regime [4]. Studies on heat transfer of fluids in cylinders by convection at different heat generation rates and temperatures were performed by Shibahara et al., [5]. Experiments were also performed using different Rayleigh numbers according to the numerical value of heat flux input, rectangular box length and initial properties of the fluid and defined Prandtl number identifying three different stages, namely conduction through the fluid layer, Rayleigh-Bénard convection and formation of longitudinal rolls [6]. Other studies were aimed to validate theoretical correlations that take part in fluid flow and heat transfer characteristics in microchannels (i.e. Nusselt number) [7,8]

Cooling system on computers is normally unnoticed by the user while using the device but it is a key element for reliable operation and correct functioning of the device. Without the presence of a cooling system, the heat generated while operating the instrument would cause overheating, damage and not only the breakdown of the system but also could represent a risk to users' health [9]. The proper design of the cooling system has to be compact and also efficient. During the operation of a computer, the temperature of some parts of the component could reach up to $100{ }^{\circ} \mathrm{C}$. Heat transfer plays an important role in controlling the temperature by distributing the heat generated to fins located in the electronic device. A fan is used to circulate the air which adsorbs and release the heat. There exist several alternatives to cool a system, among the most common are by air and by water (watercooling). Tubes containing copper filaments and water in liquid state are in continuous contact with the electronic parts where heat is generated. Transfer of heat occurs from the computer microprocessors and heated components of the device to the tubes due to conduction. Inside the cavity of the tube, the temperature increases as water adsorbs the heat, evaporates and changes the gaseous state. Heated water vapor fills the cavity of the tube surrounding the filaments and the heat starts to be distributed to the fins due to the continuous air flow provided by a near fan. When the water vapor reaches the extreme of the tubes, the heat is adsorbed and the vapor condensates in the copper filaments and changes its state to liquid. The space between the filaments is filled gradually until reaching again the hot area of the device to repeat the cooling process. Therefore, the heated vapor is continuously replaced with cooled water and the cycle continues. A gradient of temperature exists due to the difference in temperature between the solid surface and the fluid surrounding it [10-12]. Recent publications on heat transfer states the importance of simulation and modeling of thermal processes in several research fields of study [13-16].Often, the influence of parameters such as atmospheric pressure on convection process is not taken into account. In the present paper, we aim to model the variation of kinematic viscosity of cooling air and surface temperature of a transistor at different pressures. The different values of corresponding pressures depend on the elevation of the cities which were randomly selected for numerical simulation purposes. Mathematical description of air flow variation is presented to account for the regulation of surface temperature. This information would be helpful to assist in the design of new cooling devices of electronics as the control of temperature in the surface of transistors is a key element in troubleshooting thermocouple failures. Furthermore, we studied the effect of air flow in the theoretical maximum value of power dissipation that could be achieved.

\section{Description of the mathematical model}

For the analysis of the problem, we consider steady state conditions, assuming that the surface of the transistor is isothermal. Air is used to cool the upper layer of the chip surface entering at $25^{\circ} \mathrm{C}$ and flowing in parallel over the surface of the chip with length $(l)$. The remaining layers of the chip are well insulated from the surrounding. The average convection coefficient for the external flat surface of the chip located at distance (L) from the leading edge is related to the local value according to equation $\bar{h}=\frac{1}{L} \int_{0}^{L} h \cdot d x$ [17]. Additionally, we suppose that the system can be confined to two dimensions if the transistor dimensions of length are assumed to be considerably greater than the thickness. This system can be represented as described in Figure 1. Considering the Newton's law of cooling, the rate of convection $(\dot{q})$ is proportional to the temperature difference as expressed in (1). The heat transfer from the solid to the stagnant fluid layer is by conduction, following Fourier's law (2)

$$
\begin{aligned}
& \dot{\mathrm{q}}=\mathrm{h}\left(\mathrm{T}_{\mathrm{S}}-\mathrm{T}_{\infty}\right) \\
& \dot{\mathrm{q}}=-\left.\mathrm{k}_{\mathrm{f}} \frac{\partial\left(\mathrm{T}-\mathrm{T}_{\mathrm{S}}\right)}{\partial \mathrm{y}}\right|_{\mathrm{y}=0}
\end{aligned}
$$

Where $h$ is the convective heat transfer coefficient $\left(\mathrm{W} / \mathrm{m}^{2} \cdot \mathrm{K}\right), T_{S}$ is the chip surface temperature $(\mathrm{K}), T_{\infty}$ is the fluid temperature $(\mathrm{K}), k_{f}$ represents the thermal conductivity of the fluid, and $T$ is the temperature at distance $(y)$ [18]. Combining (1) and (2) leads to (3) and to determine the value of $h$ we derive expression (4)

$$
h\left(T_{S}-T_{\infty}\right)=-\left.k_{f} \frac{\partial T}{\partial y}\right|_{y=0}
$$




$$
h=\left.\frac{k_{f}}{\left(T_{S}-T_{\infty}\right)} \cdot \frac{\partial\left(T_{S}-T\right)}{\partial y}\right|_{y=0}
$$

Fluid properties are normally evaluated at the film temperature, which is given by expression (5) representing the average value between the transistor surface and the surrounding fluid temperatures [19].

$$
T_{F}=\frac{\left(T_{S}+T_{\infty}\right)}{2}
$$
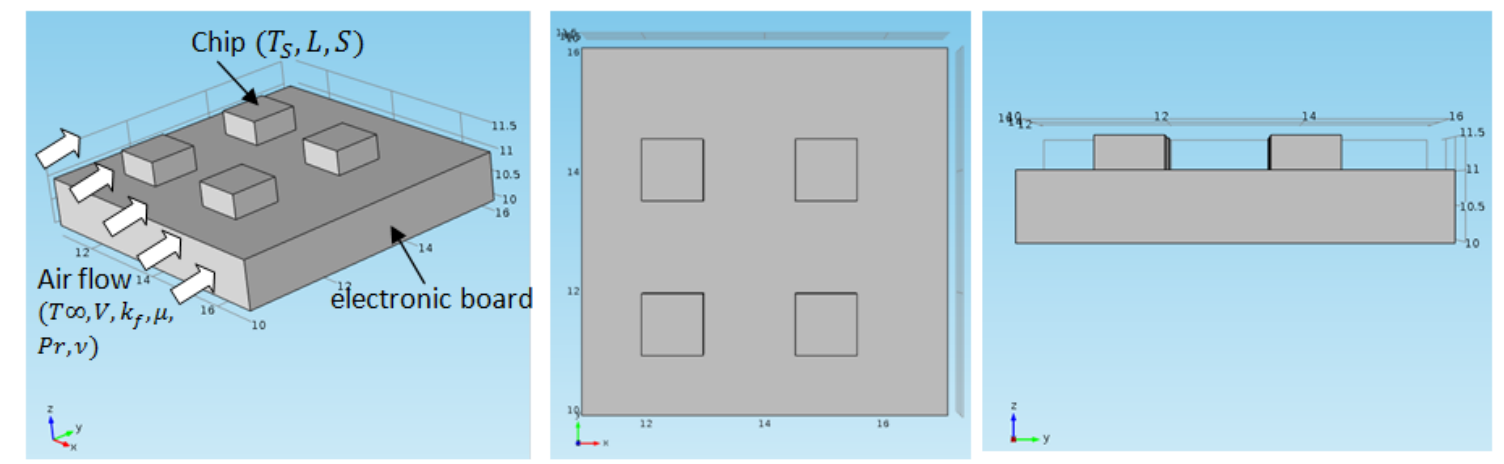

Fig. 1. Graphical representation of the system under study showing the electronic board, direction of air flow, location of transistor and geometrical parameters.

The main fluid properties that are important to consider are the thermal conductivity $\left(k_{f} ; \mathrm{W} / \mathrm{m} \cdot \mathrm{K}\right)$, the viscosity $\left(\mu ; \mathrm{N} \cdot \mathrm{s} / \mathrm{m}^{2}\right)$, Prandtl number $(\mathrm{Pr})$, kinematic viscosity $\left(v ; \mathrm{m}^{2} / \mathrm{s}\right)$ which can be obtained from Thermodynamic tables available in literature after linear regression as described through (6) to (9) for a temperature range of $100 \leq T,(K) \leq 550$

$$
\begin{aligned}
& v=\left[-2.072+0.0276 T_{F}+1.078 \times 10^{-4}{T_{F}}^{2}\right] \times 10^{-6} \\
& \mu=\left[6.109+0.6945 T_{F}-3.323 \times 10^{-4}{T_{F}}^{2}\right] \times 10^{-7} \\
& k_{f}=\left[-0.0386+0.097 T_{F}-3.1 \times 10^{-5}{T_{F}}^{2}\right] \times 10^{-3} \\
& \operatorname{Pr}=\left[0.8396-6.2857 \times 10^{-4} T_{F}+6.32 \times 10^{-7}{T_{F}}^{2}\right]
\end{aligned}
$$

Then, for the case of air at $25^{\circ} \mathrm{C}$ at sea level $(P=1$ atm $)$, the parameters are $v=1.5726 \times 10^{-5} \mathrm{~m}^{2} / \mathrm{s}, \mu=$ $1.8356 \times 10^{-5} \mathrm{~N} \cdot \mathrm{s} / \mathrm{m}^{2}, k=0.0261 \mathrm{~W} / \mathrm{m} \cdot \mathrm{K}, \operatorname{Pr}=0.7084$

Reordering equation and multiplying both sides by length $(L)$ we obtain

$$
\frac{h L}{k_{f}}=\left.\frac{L}{\left(T_{S}-T_{\infty}\right)} \frac{\partial\left(T-T_{S}\right)}{\partial y}\right|_{y=0}
$$

were the term $h L / k_{f}$ represents the dimensionless Nusselt parameter which expresses the relationship between the heat transfer by convection and the heat transfer by conduction across the boundary[20]. This parameter is function of Reynolds and Prandtl numbers. For Reynolds number in the range $10^{4} \leq R e \leq 5 \times 10^{4}$, the Nusselt number can be evaluated from the expression $N u=a R e^{b} \operatorname{Pr}^{c}$, were $a, b, c$ are defined constant values depending on the geometry of the solid and Reynolds number. Particularly, for turbulent flow, the Nusselt number takes the form of $N u=0.023 \operatorname{Re}^{4 / 5} \operatorname{Pr}^{1 / 3}$ for 0.6 $\leq P r \leq 60$ based on Chilton-Colburn analogy [21]. Moreover, from the definition of Reynolds number: $R e=V x / v$, and evaluating when $x=L$ leads to $R e=V L / v$. Thus

$$
\frac{h L}{k_{f}}=0.023\left[\frac{V L}{v}\right]^{4 / 5} \operatorname{Pr}^{1 / 3}
$$

Following from expression (11), we can obtain the value of the local heat transfer coefficient

$$
h=\frac{k_{f}}{L^{1 / 5}} \cdot 0.023\left[\frac{V}{v}\right]^{4 / 5} \operatorname{Pr}^{1 / 3}
$$




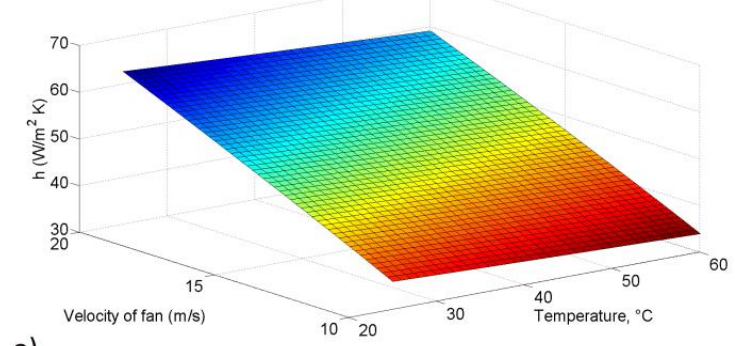

a)

Fig. 2. Local heat transfer coefficient profile as function of velocity of input air $(\mathrm{m} / \mathrm{s})$, Temperature $\left({ }^{\circ} \mathrm{C}\right)$ and distance $(\mathrm{mm})$

As described in figure 2, the value of convective heat transfer coefficient does not vary with the temperature. However, the distance of the transistor from the leading edge has an impact in increasing the value of $h$. From expression (1), it is clear that the local surface temperature $\left(T_{s}\right)$ can be calculated as expressed in (13) and depicted in Figure 3 where the variation of chip temperature is described as function of chip dimensions and convective coefficient. Accordingly, Figure 3b) shows the influence of air velocity and chip dimensions in temperature profile.

$$
T_{S}=\frac{\dot{q}}{h}+T_{\infty}=\frac{q}{A \cdot h}+T_{\infty}
$$
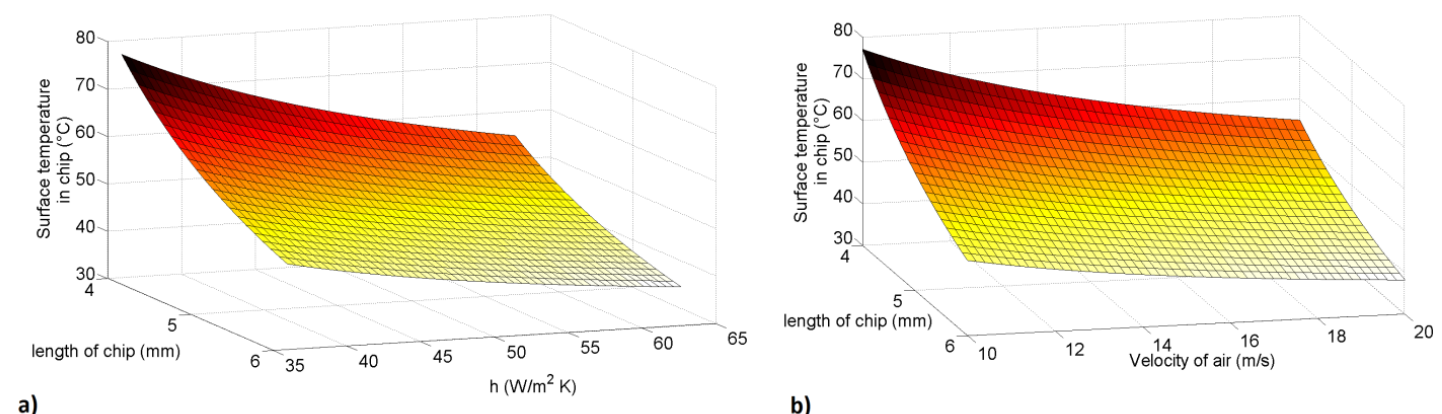

b)

Fig. 3. Temperature on the surface of the chip variation $\left({ }^{\circ} \mathrm{C}\right)$ as function of length $(\mathrm{mm}), \mathrm{h}(\mathrm{W} / \mathrm{m} 2 \cdot \mathrm{K})$ and input air velocity $(\mathrm{m} / \mathrm{s})$.

We proceed to calculate the influence of atmospheric pressure on the cooling performance of the electronic device. We select a diversity of cities with an altitude between $31 \mathrm{~m}$ and $2240 \mathrm{~m}$ as described in Table 1 . Pressure is determined as described in (14)

$$
P=101.325\left[1-2.25577 \times 10^{-5} \cdot h\right]^{5.25588}
$$

were $h$ is the altitude of the city $(m)$ and Pressure is given in $k P a$

\begin{tabular}{|c|c|}
\hline Altitude (m) & Pressure (kPa) \\
\hline 2240 & 77.15 \\
\hline 2147 & 78.05 \\
\hline 1804 & 81.45 \\
\hline 1537 & 84.17 \\
\hline 1137 & 88.39 \\
\hline 530 & 95.12 \\
\hline 31 & 100.95 \\
\hline
\end{tabular}

Table 1. Variation of pressure from selected cities around a country with corresponding values of altitude

In case of ideal gases we have $\rho=P / R T$, in which $\rho$ is constant for incompressible liquids. As the kinematic viscosity is $v=\mu / \rho$, then $\mu=v P / R T$. Considering case 1 the conditions at atmospheric pressure $\left(P_{l}\right)$ and case 2 the pressure at different city $\left(P_{2}\right)$, the value of viscosity does not change with pressure, then 


$$
\begin{aligned}
& \mu_{1}=\mu_{2} \\
& \frac{v_{1} P_{1}}{\mu_{1} R T_{1}}=\frac{v_{2} P_{2}}{R T_{2}} \\
& v_{2}=\frac{v_{1} P_{1}}{P_{2}} \\
& v_{2}=\frac{\left(1.5726 \times 10^{-5} \mathrm{~m}^{2} / \mathrm{s}\right)(101.325 \mathrm{kPa})}{P_{2}}=\frac{0.001593}{P_{2}}
\end{aligned}
$$

Kinematic viscosity relates the ability to transmit momentum disturbance with the ability to sustain momentum disturbance. As a result, the value of convective heat transfer coefficient and the temperature at the chip surface at different pressure can be calculated from expressions (19) and (20) respectively

\begin{tabular}{|c|c|c|c|c|c|}
\hline \multirow[t]{2}{*}{ Pressure (kPa) } & \multirow[t]{2}{*}{$v\left(\mathrm{~m}^{2} / \mathrm{s}\right)$} & \multicolumn{2}{|c|}{$V f=10 \mathrm{~m} / \mathrm{s}$} & \multicolumn{2}{|c|}{$V f=20 \mathrm{~m} / \mathrm{s}$} \\
\hline & & $h\left(W / m^{2} \cdot K\right)$ & $\mathrm{T}\left({ }^{\circ} \mathrm{C}\right)$ & $h\left(W / m^{2} \cdot K\right)$ & $\mathrm{T}\left({ }^{\circ} \mathrm{C}\right)$ \\
\hline 77.15 & $21 \times 10^{-6}$ & 28.9 & 89.73 & 69.59 & 51.79 \\
\hline 78.05 & $20.4 \times 10^{-6}$ & 29.16 & 89.13 & 70.24 & 51.54 \\
\hline 81.45 & $19.5 \times 10^{-6}$ & 30.17 & 86.97 & 72.67 & 50.64 \\
\hline 84.17 & $18.92 \times 10^{-6}$ & 30.98 & 85.36 & 74.61 & 49.97 \\
\hline 88.39 & $18 \times 10^{-6}$ & 32.21 & 83.04 & 77.59 & 49 \\
\hline 95.12 & $16.7 \times 10^{-6}$ & 34.16 & 79.72 & 82.28 & 47.63 \\
\hline 100.95 & $15.78 \times 10^{-6}$ & 35.83 & 77.15 & 86.29 & 46.57 \\
\hline
\end{tabular}

$$
\begin{aligned}
& h_{2}=\frac{k_{f}}{L^{1 / 5}} \cdot 0.023\left[\frac{P_{2} V}{0.001593}\right]^{4 / 5} \operatorname{Pr}^{1 / 3} \\
& T_{S}=\frac{q}{A \cdot h_{2}}+T_{\infty}
\end{aligned}
$$

Table 2. Corresponding values of $h$ and chip Temperature at given values of air flow speed and Pressure

This data is represented in Figure 4 for the limit of air velocity flow studied $(10 \mathrm{~m} / \mathrm{s}-20 \mathrm{~m} / \mathrm{s})$. As pressure decreases (higher altitude) the temperature on the transistor surface is higher. Using A speed of $10 \mathrm{~m} / \mathrm{s}$ the maximum chip temperature at normal pressure is $77^{\circ} \mathrm{C}$ but in a city with different altitude, the temperature could reach $89.73{ }^{\circ} \mathrm{C}$ which is a significant variation and should not be considered irrelevant. In order to reduce the temperature, air speed should be increased. This can be calculated from expression (21)

$$
V=v\left[\frac{h L^{1 / 5}}{k_{f} 0.023 \operatorname{Pr}^{1 / 3}}\right]^{5 / 4}
$$

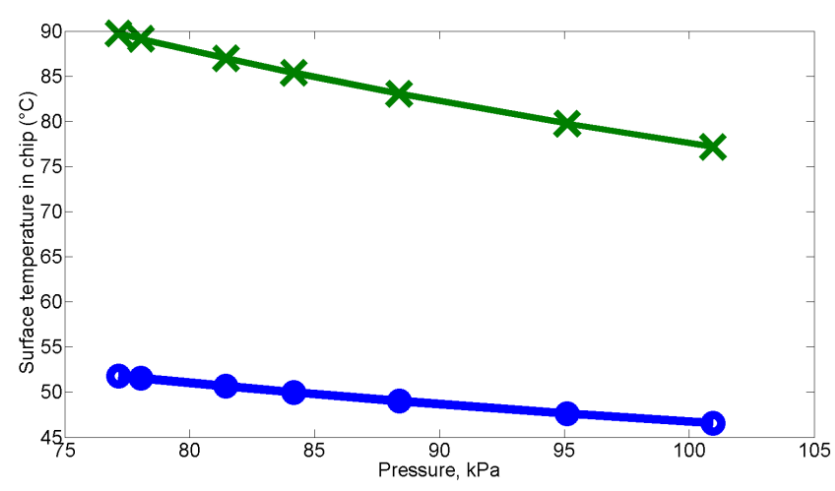

Fig. 4. Chip surface temperature range for selected values of input air flow $(10 \mathrm{~m} / \mathrm{s} \times ; 20 \mathrm{~m} / \mathrm{s} \bullet$ ). 


\begin{tabular}{|c|c|c|c|c|c|}
\hline \multirow[t]{2}{*}{ Pressure (kPa) } & \multirow[t]{2}{*}{$v\left(m^{2} / s\right)$} & \multicolumn{2}{|c|}{$\begin{array}{c}v=1.57 \times 10^{-5} m^{2} / s \\
h=35.93 \mathrm{~W} / m^{2} \cdot \mathrm{K}\end{array}$} & \multicolumn{2}{|c|}{$\begin{array}{c}v=1.57 \times 10^{-5} m^{2} / s, h= \\
62.57 \mathrm{~W} / m^{2} \cdot \mathrm{K}\end{array}$} \\
\hline & & $\mathbf{T}$ & Vf & $\mathbf{T}$ & Vf \\
\hline 77.15 & $21 \times 10^{-6}$ & 89.73 & 13.3 & 51.79 & 26.26 \\
\hline 78.05 & $20.4 \times 10^{-6}$ & 89.13 & 12.98 & 51.54 & 25.96 \\
\hline 81.45 & $19.5 \times 10^{-6}$ & 86.97 & 12.44 & 50.64 & 24.88 \\
\hline 84.17 & $18.92 \times 10^{-6}$ & 85.36 & 12.03 & 49.97 & 24.07 \\
\hline 88.39 & $18 \times 10^{-6}$ & 83.04 & 11.46 & 49 & 22.92 \\
\hline 95.12 & $16.7 \times 10^{-6}$ & 79.72 & 10.65 & 47.63 & 21.3 \\
\hline 100.95 & $15.78 \times 10^{-6}$ & 77.15 & 10.03 & 46.57 & 20.07 \\
\hline
\end{tabular}

Table 3. Readjustment of air velocity to cool the temperature on the surface of the transistor at same levels as tested at 1 atm

Now we proceed to determine the influence of air velocity at $25^{\circ} \mathrm{C}$ on the maximum amount of power dissipation as a function of air velocity. Considering that the maximum recommended temperature in the transistor surface should not be more than $85^{\circ} \mathrm{C}$ for reliable operation over prolonged periods of time, the properties of air at the film temperature, which is given by $T_{F}=(85+25) / 2=55^{\circ} \mathrm{C}$ are $v=1.86 \times 10^{-5} \mathrm{~m}^{2} / \mathrm{s}, \mu=1.98 \times 10^{-5} \mathrm{~N} \cdot \mathrm{s} / \mathrm{m}^{2}, \mathrm{k}=$ $0.0285 \mathrm{~W} / \mathrm{m} \cdot \mathrm{K}, \mathrm{Pr}=0.7014$. We considering an emissivity of 0.8 and performing an energy balance on the chip which is stagnant in a dielectric board with a surrounding temperature of $25^{\circ} \mathrm{C}$. The graphical description of power dissipation can be observed in Figure 5.

$$
\begin{aligned}
& P_{c}=\dot{q}+\dot{q}_{r}=h S\left(T_{S}-T_{\infty}\right)+h_{r} S\left(T_{S}-T_{\text {sur }}\right) \\
& h_{r}=\varepsilon \sigma\left(T_{S}+T_{\text {sur }}\right)\left(T_{S}^{2}-{T_{\text {sur }}}^{2}\right) \\
& P_{c}=h S\left(T_{S}-T_{\infty}\right)+\varepsilon \sigma S\left(T_{S}+T_{\text {surrounding }}\right)\left(T_{S}{ }^{2}-T_{\text {surrounding }}{ }^{2}\right)\left(T_{S}-T_{\text {surrounding }}\right) \\
& P_{c}=S\left[\frac{k_{f}}{L^{1 / 5}} \cdot 0.023\left[\frac{V}{v}\right]^{4 / 5} \operatorname{Pr}^{1 / 3}\right]\left(T_{S}-T_{\infty}\right)+\varepsilon \sigma S\left(T_{S}+T_{\text {sur }}\right)\left(T_{S}{ }^{2}-T_{\text {sur }}{ }^{2}\right)\left(T_{S}-T_{\text {sur }}\right)
\end{aligned}
$$

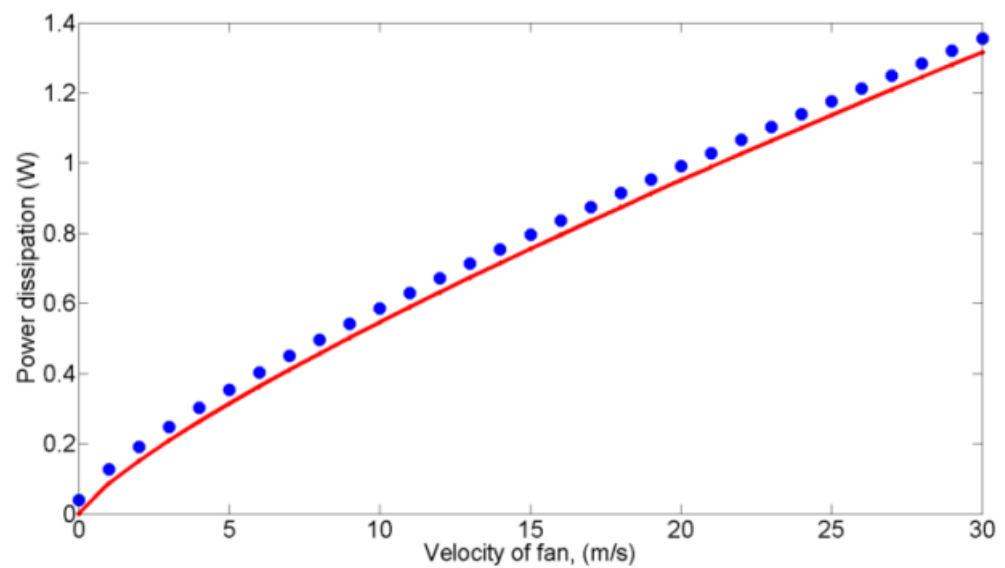

Fig. 5. Power dissipation profile as function of velocity of inlet air considering a maximum of $30 \mathrm{~m} / \mathrm{s}$ with radiation contribution (dotted) and without radiation effect (continuous).

The convective heat transfer coefficient increases with the velocity of air in the same proportion as the power of dissipation. This can be seen in Figure 6 were it is plotted the value of $h$ at different values of inlet air speed. Power dissipation increases with the velocity of air. The effect of radiation increases at a constant rate the dissipation of heat $(0.04 \mathrm{~W})$ while the convective heat transfer coefficient reaches a maximum value of $82.2 \mathrm{at} 30 \mathrm{~m} / \mathrm{s}$. Accordingly, it is also possible to evaluate an average convection coefficient according to the integral over a range of the leading edge distance. 


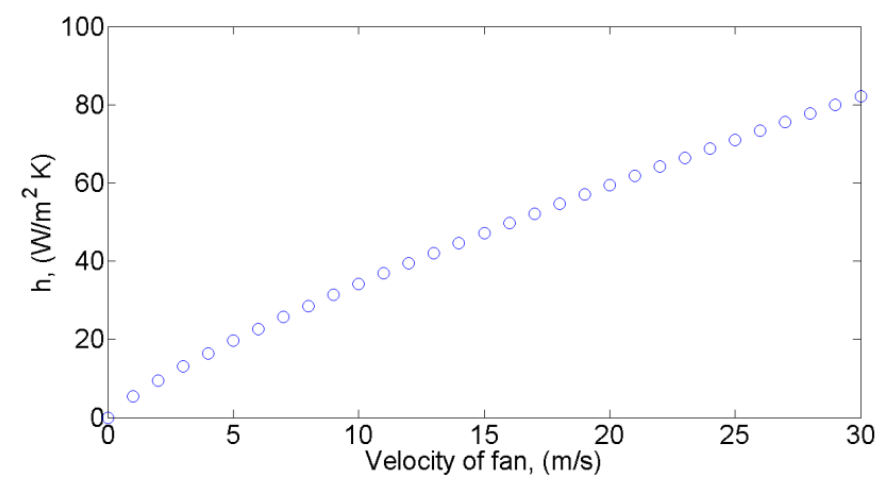

Fig. 6. Influence of air cooling velocity speed $(0-30 \mathrm{~m} / \mathrm{s})$ in heat transfer coefficient.

Variation of elevation affects several thermodynamic properties. The air is less dense at higher elevation, which decreases the atmospheric pressure value. Boiling point is other property that is affected as it decreases with the increment in elevation due to the effect of vapor pressure. In the case of convective heat transfer, there are several dimensional parameters that are important, namely Nusselt number, Reynolds number Prandtl number, and Rayleigh number. After Rayleigh number reaches certain values, the dominant mechanism is convection, rather than conduction. These values are strongly dependent on the characteristics of the system like the shape of the solid, fluid state (gas or liquid), viscosity and kinematic viscosity of the fluid, heat capacity of the air that is used for cooling, as well as the thermal conductivity, among others. Cooling process is affected considerably when the process is performed at different altitudes as it has been demonstrated by the different value of surface temperature $\left(12.58{ }^{\circ} \mathrm{C}\right.$ difference $)$ achieved when the device is used in cities above $2240 \mathrm{~m}$. Adjustments in the input air flow have to be made in order to compensate for this difference. This has a big impact in the design of new types of electronic devices which should take into consideration whether or not some changes have to me made according to the maximum allowed temperatures recommended for the components to maintain or improve their performance.

\section{Conclusion}

Mathematical modeling and simulation is an important element in several applications in many different fields of sciences such as chemistry, physics, mechanics, biology, and electronics among others. The study of fluid flow through a hot surface that allows the distribution of heat due to a temperature gradient is a practical problem that faces many challenging problems. Numerical simulation and modeling are tools that are frequently used to understand many processes and be applied to real cases to improve the design and its performance. In this paper we have used numerical simulation to study the variation of temperature on a transistor that is heated on an electronic device and is subject to the effect of different pressures. This is the case of using the device in different cities as the pressure changes with altitude and more important the density of the air since this parameter increases proportionally to the increment in pressure. Accordingly, at constant mass flow rate a decline in density causes a linear drop in the pressure. Many fans that are manufactured conventionally cool at constant speed even with the change of pressure or flow rate due to the design of blades which run at constant speed. The pressure output of the fan is strongly connected with the density of the air. Even at constant volumetric flow rate values a drop in mass flow rate with density is observed. Other type of fans is called slip fans, which allows the use of different speeds from the motor driving. This is extremely important from the point of view of electronic and mechanical cooling design for the control of temperature. In this type of fans, changes in altitude do not causes a drastic variation in the pressure flow rate curves in comparison to the use of conventional fans. One of the most important parameters to take into consideration for the effect of cooling through convection is the mass flow of fluid. When the air flow mass in the system is increased, the rise in temperature is lower. For example, using a flow of $10 \mathrm{~m} / \mathrm{s}$, a temperature near $77^{\circ} \mathrm{C}$ can be achieved in the surface of the chip but this temperature decreases up to $46{ }^{\circ} \mathrm{C}$ when the speed is doubled. In the numerical study range of elevation $(31-2240 \mathrm{~m})$ the temperature values achieved using fans with $10 \mathrm{~m} / \mathrm{s}$ leads to temperatures between $77.15{ }^{\circ} \mathrm{C}$ and $89.73{ }^{\circ} \mathrm{C}$ while in the case of doubling the air mass flow the temperature range is between $46.57{ }^{\circ} \mathrm{C}$ and 51.79 . This decrement of temperature is a key element in the correct functioning and maintenance of devices that generates heat such as the case of electronics. Selection of fans appropriate for cooling of electronic devices should be base on the proper interpretation of fan supply curve and system pressure drop, particularly in the identification of stable operating points with enough flow rates. At higher altitudes, is important to take into account the influence of low density and temperature on pressure drop. Variation of volumetric flow rate is related to the type of fan used. This study allows us to evaluate the variation of temperature and to understand the importance of fluid flow speed in controlling the heating rate. The value of heat flux is restricted to the maximum temperature that the chip can resist after technical and thermal characteristics of design. Additionally, we studied the maximum amount of power dissipation as a function of air velocity considering a maximum of $30 \mathrm{~m} / \mathrm{s}$ with radiation contribution and without radiation effect. Other consideration that could be incorporated in further studies is the influence of temperature in the surroundings (i.e. temperatures during winter and summer seasons), particularly the hot days in summer which would characterize the design for critical and worst conditions. 


\section{Acknowledgments}

This work was supported by the Ministry of Education, Youth and Sports of the Czech Republic within the National Sustainability Programme project No. LO1303 (MSMT-7778/2014) and also by the European Regional Development Fund under the project CEBIA-Tech No. CZ.1.05/2.1.00/03.0089. Further it was supported by Grant Agency of the Czech Republic - GACR 588 P103/15/06700S and by Internal Grant Agency of Tomas Bata University in Zlin under the project No. IGA/CebiaTech/2017/004. L.A.B.P author also thanks the doctoral scholarship provided by the National Council for Science and Technology (CONACYT) and the Council for Science and Technology of the State of Guanajuato (CONCYTEG) in Mexico.

\section{References}

[1] Incropera, F. P., DeWitt, D. P., Bergman, T. L., \& Lavine Adrienne S. (2007). Fundamentals of Heat and Mass Transfer, John Wiley \& Sons Inc, ISBN: 978-1-119-32042-5, United States.

[2] Lienhard V, J. H., \& Lienhard V, J. H. (2004). A Heat Transfer Textbook Dover, ISBN-10: 0486479315, United States

[3] Vogel, J., Felbinger, J., \& Johnson, M. (2016). Natural convection in high temperature flat plate latent heat thermal energy storage systems. Applied Energy, Vol. 184, pp. 184-196. doi:10.1016/j.apenergy.2016.10.001

[4] Bareiss, M., \& Beer, H. (1984). Experimental investigation of melting heat transfer with regard to different geometric arrangements. International Communications in Heat and Mass Transfer, Vol. 11, No. 4, pp. $323-333$. doi:10.1016/0735-1933(84)90060-5

[5] Shibahara, M., Liu, Q., \& Fukuda, K. (2016). Transient natural convection heat transfer of liquid D-mannitol on a horizontal cylinder. Renewable Energy, Vol. 99, pp. 971-977. doi:10.1016/j.renene.2016.07.076

[6] Sanmiguel Vila, C., Discetti, S., Carlomagno, G. M., Astarita, T., \& Ianiro, A. (2016). On the onset of horizontal convection. International Journal of Thermal Sciences, Vol. 110, pp. 96-108. doi:10.1016/j.ijthermalsci.2016.06.019

[7] Yu, J., Kang, S.-W., Jeong, R.-G., \& Banerjee, D. (2016). Experimental validation of numerical predictions for forced convective heat transfer of nanofluids in a microchannel. International Journal of Heat and Fluid Flow, Vol. 62, pp. 203-212. doi:10.1016/j.ijheatfluidflow.2016.11.001

[8] Kim, B. (2016). An experimental study on fully developed laminar flow and heat transfer in rectangular microchannels. International Journal of Heat and Fluid Flow, Vol. 62, pp. $224-232$. doi:10.1016/j.ijheatfluidflow.2016.10.007

[9] Yeh, L. T. (1995). Review of Heat Transfer Technologies in Electronic Equipment. Journal of Electronic Packaging, Vol. 117, No. 4, pp. 333. doi:10.1115/1.2792113

[10] Jang, S. P., Kim, S. J., \& Paik, K. W. (2003). Experimental investigation of thermal characteristics for a microchannel heat sink subject to an impinging jet, using a micro-thermal sensor array. Sensors and Actuators A, Vol. 105, pp. 211-224. doi:10.1016/S0924-4247(03)00103-1

[11] Baby, R., \& Balaji, C. (2013). Thermal optimization of PCM based pin fin heat sinks: An experimental study. Applied Thermal Engineering, Vol. 54, No. 1, pp. 65-77. doi:10.1016/j.applthermaleng.2012.10.056

[12] Kalbasi, R., \& Salimpour, M. R. (2015). Constructal design of phase change material enclosures used for cooling electronic devices. Applied Thermal Engineering, Vol. 84, pp. 339-349. doi:10.1016/j.applthermaleng.2015.03.031

[13] Nunez-Vega, A-M; Hugenschmidt, S \& Hofacker, W (2012). Numerical Simulation of the Convective Drying of Apple Slices, Chapter 29 in DAAAM International Scientific Book 2012, pp. 339-356, B. Katalinic (Ed.), Published by DAAAM International, ISBN 978-3-901509-86-5, ISSN 1726-9687, Vienna, Austria DOI: 10.2507/daaam.scibook.2012.29

[14] Marek, V (2016). Basic Research of Thermal Transfer Simulations, Proceedings of the 27th DAAAM International Symposium, pp.0578-0585, B. Katalinic (Ed.), Published by DAAAM International, ISBN 978-3-902734-08-2, ISSN 1726-9679, Vienna, Austria DOI: 10.2507/27th.daaam.proceedings.085

[15] Gerlich, V., Zálešák, M.(2010) Experimental validation of heat transfer model, Annals of DAAAM and Proceedings of the International DAAAM Symposium, 2010, pp. 969-970. ISSN 1726-9679, Zadar

[16] Chval, Z \& Raz, K (2016). Effect of Heat Load on a Mechanical Forging Press, Proceedings of the 27th DAAAM International Symposium, pp.0344-0348, B. Katalinic (Ed.), Published by DAAAM International, ISBN 978-3902734-08-2, ISSN 1726-9679, Vienna, Austria DOI: 10.2507/27th.daaam.proceedings.050

[17] Holman, J. P. (2009). Heat transfer, McGraw-Hill, ISBN: 0073529362, London

[18] Cengel, Y., \& Turner, R. (2001). Fundamentals of Thermal-Fluid Sciences, McGraw-Hill Higher Education.ISBN: 0078027683 , New York.

[19] Welty, J., Wicks, C., \& Wilson, R. (2008). Fundamentals of Momentum, heat, and Mass Transfer. Jonh Wiley and Sons, ISBN: 978-0470128688, Mexico.

[20] Bird, R. B., Stewart, W. E., \& Lightfoot, E. N. (2002). Transport Phenomena. John Wiley \& Sons, Inc. ISBN: 0470115394, New York

[21] Tsilingiris, P. T. (2010). Modeling heat and mass transport phenomena at higher temperatures in solar distillation systems - The Chilton-Colburn analogy. Solar Energy, Vol. 84, No. 2, pp. 308-317. doi:10.1016/j.solener.2009.11.012 